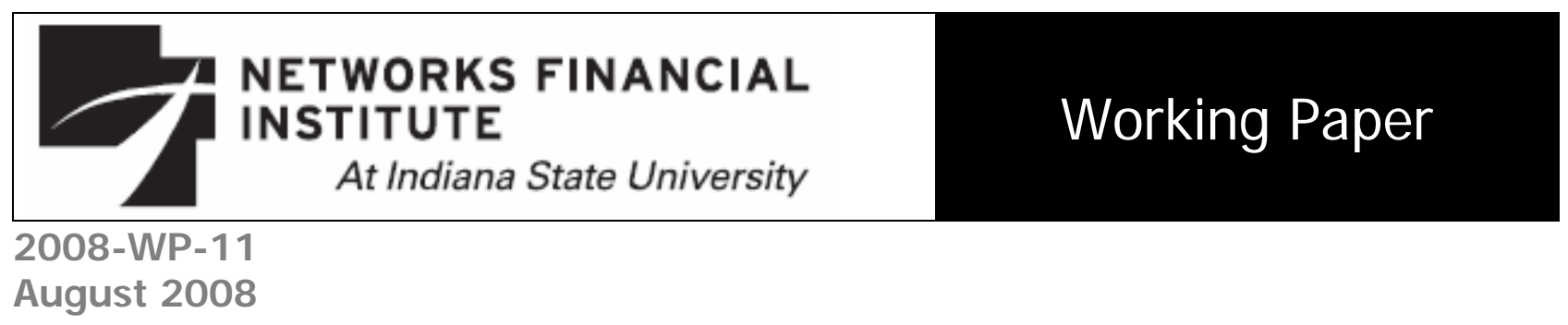

\title{
Intergenerational Transfers and Expectations: A Note on How a Ponzi Scheme Affects Saving H. Yigit Aydede
}

Abstract: This paper examines the distributional characteristics of parametric reforms carried out when a planner faces an unexpected adverse shock to the pay-as-you-go system. When transfers are used to balance the system, we show that, even if the planner chooses a Ponzi scheme in the face of permanent adverse shocks, agents' expectations can deviate from the actual public policy, depending on its sustainability in people's eyes. When the young are forced to share some of the adverse shock by raising their contributions to the system, the total consumption increases unambiguously in the short run, only if this policy is credible and binding. While this increase critically depends on the difference in marginal propensities to consume of living generations, as long as this policy is perceived as unsustainable by the young, the total consumption falls in the long term even if the planner keeps the same policy in the future. This result is different than the common verdict of many studies: when transfers are used to reform a PAYG system, it turns out to be an unsustainable Ponzi scheme, which leads to an increase in total consumption and decline in national saving.

About the Author: Yigit Aydede is Assistant Professor of Economics at the Sobey School of Business at Saint Mary's University in Halifax. Previously he was at the University of Windsor, Canada. He received his MBA degree in 2004 and his PhD degree in economics in 2006, both from the University of Delaware. In addition to business experience in banking and insurance sectors, he has extensive university teaching experience. His research interests include the economics of aging, social security, public finance, and applied macroeconomics. His present research focuses on the public social security systems in developing countries. He is currently investigating the effects of unfunded social security systems on intergenerational resource transfers and labor force participation under developing country conditions. He is also working on generational accounting in Turkey that has one of the most generous social security systems in the OECD region.

Keywords: Social Security, Expected Intergenerational Transfers, Life-Cycle Saving, Consumption.

\section{J EL Classification: J 1, H31, E21.}

The author is grateful to Networks Financial Institute for its financial support for this study and is especially indebted to Professor Murat Aydede at the University of British Columbia for his invaluable contributions. The views expressed are those of the individual author and do not necessarily reflect official positions of Networks Financial Institute. Please address questions regarding content to Yigit Aydede atyigit.aydede@smu.ca. Any errors or omissions are the responsibility of the author. NFI working papers and other publications are available on NFI's website (www. networksfinancialinstitute.org). Click "Research" and then "Publications/Papers." 


\section{Intergenerational Transfers and Expectations: A Note on How a Ponzi Scheme Affects Saving}

\section{H. Yigit Aydede}

The effect of intergenerational wealth transfers on saving is not a new topic and has been extensively investigated in the literature for the last four decades. An unfunded social security system is a transfer scheme among generations and when introduced, the first generations receive an unexpected windfall. It is well known that, in the absence of altruistic transfers, imperfect capital markets, and accidental bequests, this initial wealth transfer reduces saving and increases consumption. If the productive capital earns less than the sum of growth in population and productivity, this reduction in saving can be optimized by a policy to increase welfare for each succeeding generation. When the economy is dynamically efficient, however, the system becomes a zero-sum game: the gain for the first generations is offset by the loss to all future generations. If so, there is no optimal policy of pay-as-you-go (PAYG) systems, because the removal of the system increases saving and wellbeing of all future generations. However, even if the existence of the system is not optimal, every time an adverse shock hits, a planner ${ }^{1}$ has to bring the system back to balance by a parametric reform. ${ }^{2}$

This paper studies the role of generational transfers from a different perspective: the effect of intergenerational wealth distribution initiated by an adverse shock to a non-optimal PAYG system in a simple two-period overlapping generations model. After its startup, if the implicit rate of return for the system is not different than what a private investment can earn, transfers by a PAYG system do not alter lifetime wealth of generations. However, unlike an unexpected introduction of a PAYG system, when transfers are used to balance its budget, every generation have expectations not only about the fairness of the system, but also about its sustainability. Therefore, analyzing distributional effects of an existent PAYG system on consumption requires an explicit model in which the system faces adverse shocks and the planner uses transfers to balance the system.

This paper, unlike others, examines the distributional characteristics of parametric reforms that have to be carried out when the planner faces an unexpected adverse shock to the PAYG system. When transfers are used to balance the system, this study shows that, even if the planner chooses a Ponzi scheme ${ }^{3}$ in the face of permanent adverse shocks, agents' expectations can deviate from the actual public policy depending on its sustainability in the eyes of people. When the young are forced to share some of the adverse shock by raising their contributions to the system, the total consumption increases unambiguously in the short run, only if this policy is credible and binding. While this increase critically depends on the difference in marginal propensities to consume of living generations, as long as this policy is perceived as unsustainable by the young, the total consumption falls in the long term even if the planner keeps the same policy in the future. This result is different than the common verdict of many studies: when transfers are used to reform

\footnotetext{
${ }^{1}$ In this study, "planner" refers to a public finance or social planner who is responsible for managing public, or government, programs.

${ }^{2}$ The planner has to satisfy the budget of the system. If the reform, which changes benefits and contributions, is postponed, public borrowing must be used, which shifts the entire burden of an adverse shock to coming generations.

${ }^{3}$ Ponzi schemes are a type of illegal pyramid scheme named for Charles Ponzi, who duped thousands of New England residents into investing in a postage stamp speculation scheme back in the 1920s. Decades later, the Ponzi scheme continues to work on the 'rob-Peter-to-pay-Paul' principle, as money from new investors is used to pay off earlier investors until the whole scheme collapses. At some point the schemes get too big, the promoter cannot raise enough money from new investors to pay earlier investors, and many people lose their money.
} 
a PAYG system, it turns out to be an unsustainable Ponzi scheme, which pulls national consumption up and national saving down. ${ }^{4}$

This paper is related to a large literature on optimality of PAYG policies (Samuelson 1958, 1975; Feldstein, 1985), on effects of social security on saving (Auerbach and Kotlikoff, 1983a; Feldstein, 1974; Ando and Modigliani, 1963), on intergenerational redistribution of wealth by PAYG (Feldstein, 1976; Kotlikoff, 2001; Auerbach and Kotlikoff, 1983b), and on the timeconsistency problem in generational policies (Calvo and Obstfeld, 1988). The model is explained in Section 1 and the results interpreted in Section 2.

\section{The model}

There are three major competing theories in testing whether or not social security affects saving: the life-cycle model (Modigliani and Brumberg 1954, Ando and Modigliani 1963, and Modigliani 1986), the infinite-horizon model (Barro 1974), and the Keynesian model. Unlike the infinite-horizon model, in the life-cycle model Ricardian equivalence fails so that the time path of taxes has real impact on the economy by changing the severity of tax distortion on different generations. It breaks the link between the horizon of private individuals and that of the government. The effect of a PAYG system on saving can be explained by the fact that it redistributes wealth among generations with different marginal propensities to consume (MPC) out of lifetime resources. If MPC depends on age, as suggested by the life-cycle theory, people save more (consume less) while they are young and consume more as they get older. If generational links are not as altruistic as indicated by the infinite horizon model, any public policy that redistributes the wealth from younger generations to older ones causes national consumption to increase and national saving to fall ${ }^{5}$ - even if social security wealth for these generations is zero.

To show it formally, we use a two-period overlapping generations model where there is no productive capital and identical individuals are endowed by $w$ for their inelastic labor supply.

They save $(s)$ in the first period, and retire and spend their saving in the second period. There is no uncertainty in lifetime, liquidity constraint, bequest, and growth in endowment. To avoid defining the utility function explicitly, we assume that the real interest rate $(r)$ is equal to the personal discount rate $(\rho)$. The planner runs a balanced PAYG system where the young $(y)$ pay taxes $(t x)$ and the old $(o)$ receive benefits $(b)$ as defined below:

$$
R_{t} b_{t}=L_{t} t x_{t} \Rightarrow b_{t}=\left(1+n_{t}\right) t x_{t}
$$

where $R$ and $L$ stand for numbers of retirees and workers respectively. The population grows by $n$. We introduce an unexpected adverse demographic shock $(\theta)$ to the system, at time $(t)$ as follows.

$$
b_{t}^{*}=\left(1+n_{t}-\theta_{t}\right) t x_{t} \Rightarrow b_{t}>b_{t}^{*}
$$

\footnotetext{
${ }^{4}$ The main motivation for this paper is the curious fact that while the Turkish PAYG system has been the most generous and financially deteriorating system in the Organization of Economic Co-operation and Development (OECD) region, the private (and national) saving has been significantly higher than the averages in OECD and the European Union (EU) and increasing for the last 30 years until 2004. See (IMF, 2007) and (OECD, 2005).

${ }^{5} \mathrm{We}$ ignore the fact that the negative effect of income distribution on savings can be offset by positive population and income growths.
} 
Since we want $R_{t}$ to be equal to $L_{t-1}$ to avoid heterogeneity among retirees, we assume that adverse shocks are due to negative changes in fertility. ${ }^{6}$ Changes in population will be introduced to the system by adverse shocks as follows.

$$
n_{t+1}=n_{t}-\theta_{t}
$$

Since taxes are fixed, transfers are used to balance the system as seen below.

$$
\begin{aligned}
& b_{t}=\left(1+n_{t}-\theta_{t}\right)\left(t x+t r_{t}\right) \\
& t r_{t}=\delta_{t} \theta_{t} t x\left(1+n_{t}-\theta_{t}\right)^{-1}
\end{aligned}
$$

where $\delta$ is a policy variable and determined by the planner. It distributes the burden $(\theta t x)$ among generations such that, as it approaches one, the full burden will be shifted from the old to the young. Our setting is different from the conventional way of modeling generational transfers in PAYG systems. First, when there is a shock to the system, even in the absence of dynamic inefficiency, non-zero distribution $(\delta>0)$ may be optimal and determined by the planner's objective function. ${ }^{7}$ For instance, if the social discount rate for future generations is high enough in this function, more burden shifts to next generations (Aydede 2008). Hence, our model allows finding the optimal level of generational distribution by setting a policy variable for the planner. Second, even if expectations on future shocks are zero, as long as $\delta>0$ in the first period, every succeeding generation may have expectations on $\delta$ in the second period conditional on its value in the first period. If the planner keeps the policy variable constant, as shocks add up, every generation will face higher transfers as indicated by (4c) below.

$$
t r_{s}=\frac{t x \delta_{s} \sum_{i=t}^{s} \theta_{i}}{\left(1+n_{t}-\sum_{i=t}^{s} \theta_{i}\right)}
$$

This has to be less than or equal to $w$-tx. In other words, as shocks cumulate and approach to the point where transfers are not affordable anymore, the system gradually collapses by decreasing $\delta$, or the last generation pays the entire burden, if the system is terminated by setting $\delta$ to zero at once by the planner. This brings a possibility that the planner may decide to end the program (gradually or at once) so that the expectation about the policy variable $(\delta)$ can realistically be lower than zero. If we allow that expected benefits can be zero at time $(s)$ as follows

$$
E_{s-1} b_{s}=\operatorname{tx}\left(1+n_{t}-\sum_{i=t}^{s-1} \theta_{i}-E_{s-1} \theta_{s}\right)+t x E_{s-1} \delta_{s}\left(\sum_{i=t}^{s-1} \theta_{i}+E_{s-1} \theta_{s}\right)=0
$$

we obtain the following constraint for expectations on the policy variable:

\footnotetext{
${ }^{6}$ If we include shocks to labor force participation and longevity, the aggregation becomes more complex.

${ }^{7}$ As shown by Marini and Scaramozzino (1999), if the society cares more about the elderly, the economic existence of a PAYG system can be justified entirely on ethical grounds by setting higher social discount rates for the young.
} 


$$
1-\frac{1+n_{t}}{E_{s-1} \theta_{s}+\sum_{i=t}^{s-1} \theta_{i}} \leq E_{s-1} \delta_{s} \leq 1
$$

which is bounded at the minimum by a negative value. ${ }^{8}$

Shocks to the system and thus generational transfers are recognized by individuals when they are required to pay $t r$ and form their expectations in the first period about whether or not the system will be fair in the second period. The young can expect a fair $\left(E_{t} b_{t+1} /(1+r)-t x-t r_{t} \geq 0\right)$ or unfair $\left(E_{t} b_{t+1} /(1+r)-t x-t r_{t}<0\right)$ PAYG. The consumption path $\left(c_{y s}, c_{o s+1}\right)$ of the young, therefore, will be affected by four factors: (1) the transfer they have to pay in the first period $\left(t r_{t}\right)$; (2) shocks in the second period expected in the first period $\left(E_{t} \theta_{t+1}\right)$; (3) expectations on the government's policy in the second period $\left(E_{t} \delta_{t+1}\right)$; and (4) the government's actual policy in the second period $\left(\delta_{t+1}\right)$.

Formally, every young person faces the following problem.

$$
\operatorname{Max}_{c} u\left(c_{y t}\right)+(1+\rho)^{-1} E_{t} u\left(c_{o t+1}\right)
$$

subject to

$$
c_{y t}=w-t x-t r_{t}-s_{t}
$$

and

$$
E_{t} c_{o t+1}=(1+r) s_{t}+E_{t} b_{t+1}
$$

If the utility function is time-separable and satisfies the conventional conditions, the young at time $t$ solve this problem with the following values.

$$
\begin{aligned}
& c_{y t}=\frac{1+r}{2+r}\left[w-t x-t r_{t}+E_{t} b_{t+1}(1+r)^{-1}\right] \\
& s_{t}=1 /(2+r)\left[w-t x-t r_{t}-E_{t} b_{t+1}\right]
\end{aligned}
$$

Given all individuals recognize that the planner commits to a balanced-budget (4a), the young's expectation on benefits at $t$ becomes:

$$
E_{t} b_{t+1}=\left(1+n_{t+1}-E_{t} \theta_{t+1}\right)\left(t x+E_{t} t r_{t+1}\right) .
$$

Assuming that $E_{t} \theta_{t+1}=0$, and using (4c), we obtain

$$
\left(1+n_{t+1}\right) E_{t} t r_{t+1}=\theta_{t} t x E_{t} \delta_{t+1} .
$$

\footnotetext{
${ }^{8}$ We ignore the possibility that the planner may set $\delta$ higher than 1 .
} 
Since $\left(1+n_{t+1}\right)=\left(1+n_{t}-\theta_{t}\right)$, we can express (7a) in terms of taxes as follows.

$$
E_{t} b_{t+1}=t x\left(1+n_{t}\right)-\theta_{t} t x\left(1-E_{t} \delta_{t+1}\right)
$$

Likewise, the transfer that the young pay at time $(t-1)$ becomes:

$$
t r_{t}=\frac{\delta_{t} \theta_{t} t x}{1+n_{t}-\theta_{t}}
$$

Substituting (7c) and (7d) into (6a), we obtain

$$
c_{y t}=\frac{1}{2+r}\left[(1+r) w+\left(n_{t}-\theta_{t}-r\right) t x-\frac{(1+r) \theta_{t} t x \delta_{t}}{1+n_{t}-\theta_{t}}+\theta_{t} t x E_{t} \delta_{t+1}\right] .
$$

Expectations and the government policy on $\delta$ will determine the saving and the consumption of the young in the first period. In addition, the old also face the following consumption function at time $(t)$.

$$
c_{o t}=(1+r) s_{t-1}+b_{t}=\frac{1+r}{2+r}\left[w-t x-E_{t-1} b_{t}\right]+b_{t}
$$

Since $E_{t-1} \theta_{t}=0$, expected and realized benefits can be expressed as follows.

$$
\begin{aligned}
& E_{t-1} b_{t}=t x\left(1+n_{t}\right) \\
& b_{t}=t x\left(1+n_{t}\right)-\theta_{t} t x\left(1-\delta_{t}\right)
\end{aligned}
$$

Hence, (7f) becomes

$$
c_{o t}=\frac{1+r}{2+r} w+\frac{n_{t}-r}{2+r} t x-\theta_{t} t x\left(1-\delta_{t}\right) .
$$

As equations (7e) and (8c) indicate, if the planner sets $\delta_{t}$ to zero, the total consumption will decrease unambiguously. If the planner chooses to balance the system by setting $0<\delta_{t} \leq 1$, the effect of transfers on total consumption (and saving) at time ( $t$ ) will depend on three factors: (1) the aggregation of individual consumption functions; (2) generational differences in marginal propensity to consume (MPC); and (3) the expectations of the young on the future policy $\left(E_{t} \delta_{t+1}\right)$. In our model, MPC of the old is one. However, in the existence of altruistic transfers, imperfect capital markets, and accidental bequests, the old may have a lower MPC, which may reduce positive effects of the policy on consumption. On the other hand, as expressed by (7e), a positive correlation between expectations of the young $\left(E_{t} \delta_{t+1}\right)$ and the policy $\left(\delta_{t}\right)$ magnifies the increase in total consumption at time $(t)$. The net effect of transfers on the total consumption, 


$$
C_{t}=R_{t} c_{o t}+L_{t} c_{y t}
$$

can be observed as follows.

$$
\frac{d C_{t}}{d \delta_{t}}=R_{t} \theta_{t} t x-L_{t} \theta_{t} t x\left[\frac{1+r}{2+r}\left(1+n_{t}-\theta_{t}\right)^{-1}-\frac{1}{2+r} \frac{d E_{t} \delta_{t+1}}{d \delta_{t}}\right]
$$

Since $L_{t}=\left(1+n_{t}-\theta_{t}\right) L_{t-1}$, when we normalize $L_{t-1}$ (i.e. $\left.R_{t}\right)$ to one, $(9 \mathrm{~b})$ becomes.

$$
\frac{d C_{t}}{d \delta_{t}}=\frac{1}{2+r}\left[1+\frac{d E_{t} \delta_{t+1}}{d \delta_{t}}\left(1+n_{t}-\theta_{t}\right)\right] \theta_{t} t x
$$

As seen in (9c), the short-run effect of any generational policy on total consumption is positive only if: (1) the difference between MPCs of the old and the young is positive $(1 /(2+r)$ in our model); and (2) the aggregated effect of the generational policy on expectations of the young at $t$ is not less than negative one. As our model implies, even if future shocks are not anticipated, agents can have expectations on future transfers conditional on the transfers they paid before. Depending on how the sustainability of the planner's policy is perceived, ${ }^{9}$ the expectations on future transfers can diverge from the actual transfer policy executed by the planner. To see how this diversion affects consumption in the long-run, we assume, for the moment, that:

$$
r=n_{t}-\theta_{t}=0
$$

and

$$
E_{t} \theta_{t+1}=\theta_{t+1}=0
$$

With these assumptions (7e) becomes:

$$
c_{y t}=\frac{1}{2}\left[w-\theta_{t} t x \delta_{t}+\theta_{t} t x E_{t} \delta_{t+1}\right] .
$$

Since $c_{o t+1}=(1+r) s_{t}+b_{t+1}$ we obtain

$$
c_{o t+1}=(1+r)\left\lfloor w-t x+\theta_{t} t x \delta_{t}-c_{y t}\right\rfloor+b_{t+1}
$$

where $b_{t+1}=t x-\theta_{t} t x \delta_{t+1}$. Similar to (7e), the young also have the following consumption function at time $(t+1)$.

$$
c_{y t+1}=\frac{1}{2}\left[w-\theta_{t} t x \delta_{t}+\theta_{t} t x E_{t+1} \delta_{t+2}\right]
$$

\footnotetext{
${ }^{9}$ There can also be a time-inconsistency problem, if the planner's policy is not binding, as shown by Aydede (2008).
} 
To aggregate (11b) and (11c), we use

$$
L_{t+1}=\left(1+n_{t}-\theta_{t}\right)^{2} L_{t-1}
$$

Because $L_{t-1}$ (i.e. $R_{t}$ ) was normalized to one before and, by assumptions, $\theta_{t+1}=0$ and $n_{t+1}=n_{t}-\theta_{t}=0$, it becomes the following.

$$
L_{t+1}=\left(1+n_{t}-\theta_{t}\right)^{2} L_{t-1}=R_{t+1}=1
$$

By substituting (11b) and (11c) into

$$
C_{t+1}=R_{t+1} c_{o t+1}+L_{t+1} c_{y t+1}
$$

we obtain the following total consumption at time $(t+1)$.

$$
C_{t+1}=w+\frac{1}{2} \theta_{t} t x\left(E_{t+1} \delta_{t+2}-E_{t} \delta_{t+1}\right)+\frac{1}{2} \theta_{t} t x\left(\delta_{t+1}-\delta_{t}\right)
$$

Equation $(11 \mathrm{~g})$ means that, in the long run, even if the planner maintains its policy in each period as

$$
0<\delta_{t}=\delta_{t+1}=\ldots=\delta_{T}
$$

deteriorating expectations $\left(E_{t+1} \delta_{t+2}<E_{t} \delta_{t+1}\right)$ on the sustainability of the system can reduce the consumption. ${ }^{10}$ If the policy is binding and sustainable, that is

$$
E_{t} \delta_{t+1}=E_{t+1} \delta_{t+2}=\delta_{t}=\delta_{t+1}
$$

it becomes irrelevant, as expected, in terms of its effect on consumption in the second and subsequent periods. However, when $\delta$ is set higher than zero and not binding, people may question not only the credibility of the policy but also the sustainability of the program. If we restrict expectations on the policy as $0 \leq E_{s-1} \delta_{s} \leq 1$ and assume that the young expect an unfair PAYG in the second period by setting $E_{t} \delta_{t+1}=0$, the consumption unambiguously increases in the first period. Even if the planner keeps the same policy in the futures, as stated by (12a), and the young expect an unfair PAYG, the consumption for future periods is not affected. ${ }^{11}$ This outcome changes if we allow people to expect the program can be terminated by the planner. Therefore, if we expand the constraint for the expectations on the policy by (4e), not only the effect of the distributional policy on consumption can be negative in the second period, but also in the first period.

\footnotetext{
${ }^{10}$ Even if we relax the assumptions that $r=\left(n_{t}-\theta_{t}\right)=0$ and $E_{t} \theta_{t+1}=\theta_{t+1}=0$, the fundamental result of $(11 \mathrm{~g})$ does not change.

${ }^{11}$ If the lower bound for expectations is $E_{t} \delta_{t+1}=0$, the result of $\left(E_{t+1} \delta_{t+2}-E_{t} \delta_{t+1}\right)$ is never negative.
} 
In summary, when there is an unexpected shock in a PAYG system, transfers may be chosen by the planner to balance the system. Once the initial transfer is set, every succeeding generation can have expectations about future transfers. If the planner's policy is not credible in people's eyes, expectations can deviate from the actual policy and the existence of the system can be questioned by people. Even if the policy is set and sustained as a Ponzi scheme $\left(\delta_{t}=\delta_{t+1}=1\right)$, people might smooth their lifetime consumption by expecting otherwise. Therefore, the effect of intergenerational transfers on total consumption critically depends on people's expectations. The consumption is unambiguously ${ }^{12}$ higher in the short-run only if it is believed that the system will exist. When there is an increasing possibility that the system can be ended as the planner insists on unsustainable policies, people may expect negative transfers which in turn reduce consumption and increase saving. In fact, this reduction would be more than the amount if the planner were to set a zero-transfer policy in the first place.

\section{Conclusion}

When a PAYG system is initiated for the first time, consumption increases unambiguously. In the absence of adverse shocks, even if it is not optimal, a PAYG system can be sustainable. Except for generations at the startup, the existence of a PAYG system does not constitute wealth redistribution among generations and, therefore, transfers from the young to the old cannot affect consumption. ${ }^{13}$ PAYG systems are transfer schemes and fundamentally depend on productivity, demographic parameters, and labor market characteristics, which shape the system's budget. Changes in them force the planner to decide how to adjust the parameters to rebalance the system in the short-run. When transfers are used in these parametric "reforms," adverse shocks generate significant wealth redistributions among generations, similar to the system's introduction.

However, unlike the startup of the system, when a distribution policy for an adverse shock is set by the planner, depending on how adverse shocks are handled by the planner, people have expectations on the same policy in the future as well as on the sustainability of the system. It is well known that Ponzi schemes postpone fiscal liabilities to coming generations and hence increase consumption for living generations. Our finding adds a different perspective to this common belief: as long as people are rational and realize that the PAYG system becomes unsustainable by a Ponzi scheme at the extreme, we argue that, even if transfers lead to significant wealth transfers between different age cohorts with different MPCs, national saving can increase more than the amount that an optimal policy with zero transfers would achieve in face of adverse shocks.

\footnotetext{
${ }^{12} \mathrm{We}$ assume that the lower boundary of $E_{t} \delta_{t+1}$ is zero. However, if the policy is not binding, as in (4e), the change in consumption becomes ambiguous even in the first period.

${ }^{13}$ If we assume that the return on private investment is higher (lower) than the implicit rate of return of PAYG contributions, every generation gains (loses) the difference.
} 


\section{References:}

Ando, A. and Modigliani, F. (1963). "The Life Cycle Hypothesis of Saving: Aggregate Implications and Tests." The American Economic Review, Vol.53.1 (March): 55-84.

Auerbach, A. and Kotlikoff, L. (1983a). "An Examination of Empirical Tests of Social Security and Savings." In Helpman, E., A. Razin E. Sadka (eds.), Social Policy Evaluation: An Economic Perspective, p. 161-79.

Auerbach, A. and Kotlikoff, L. (1983b). Dynamic Fiscal Policy. NY: The Press Syndicate of the University of Cambridge.

Aydede, Y. (2008). "A Dynamic Inconsistency Problem in PAYG: A Solution to the Turkish Puzzle.” NFI Working Paper. 2008-WP-07.

http://www.networksfinancialinstitute.org/List/Publication\%20Library/Attacments/90/2008-WP08-Aydede.pdf

Barro, R. (1974). “Are Government Bonds Net Wealth?” Journal of Political Economy, Vol. 82.6 (Nov.-Dec.): 1095-1117.

Feldstein, M. (1974). "Social Security, Induced Retirement, and Aggregate Capital Accumulation.” Journal of Political Economy. Vol.82.5 (Sep.-Oct.): 905-926.

Feldstein, M. (1976). "Social Security and the Distribution of Wealth." Journal of the American Statistical Association. Vol.71.356 (Dec.): 800-807.

Feldstein, M. (1985). “The Optimal Level of Social Security Benefits.” Quarterly Journal of Economics. Vol.100.2 (May): 303-320.

International Monetary Fund (2007). “Turkey: Selected Issues.” IMF Country Report No. 07/364. (November). http://www.imf.org/external/pubs/ft/scr/2007/cr07364.pdf.

Kotlikoff, L. J. (2001). “Generational Policy.” NBER Working Paper No. 8163. (March). http://www.nber.org/papers/w8163.

Marini, G. and Scaramozzino, P. (1999). "Social Security and International Equity." Journal of Economics. Vol.70.1: 17-35.

Modigliani, F. (1986). "Life Cycle, Individual Thrift, and the Wealth of Nations." American Economic Review, Vol.76.3 (June): 297-313.

Samuelson, P. A. (1958). "An Exact Consumption-Loan Model of Interest With or Without the Social Contrivance of Money.” Journal of Political Economy. Vol.66.6 (Dec.): 467-482.

Samuelson, P. A. (1975). "Optimal Social Security in a Life Cycle Growth Model." International Economic Review. Vol.16.3 (Oct.): 539-544. 
Organization for Economic Co-operation and Development (2007). Pensions at a Glance. Public Policies across OECD Countries. Paris: OECD. http://213.253.134.43/oecd/pdfs/browseit/8107071E.pdf. 